\title{
Guatemala: On-site training and outreach increases demand for and provision of vasectomy
}

Frontiers in Reproductive Health

Follow this and additional works at: https://knowledgecommons.popcouncil.org/departments_sbsr-rh

Part of the Demography, Population, and Ecology Commons, Family, Life Course, and Society Commons, International Public Health Commons, and the Medicine and Health Commons How does access to this work benefit you? Let us know!

\section{Recommended Citation}

"Guatemala: On-site training and outreach increases demand for and provision of vasectomy," FRONTIERS OR Summary no. 67. Washington, DC: Population Council, 2007. 


\section{Guatemala Contraceptive choice OR Summary 67}

\section{On-Site Training and Outreach Increases Demand for and Provision of Vasectomy}

\begin{abstract}
A facility-based approach using team orientation, on-site training, and counseling for potential clients significantly enhanced demand for vasectomy services. Services were sustained following the intervention, and the approach is being expanded to six other facilities.
\end{abstract}

\section{Background}

About one-third of Guatemalan women use modern contraceptives and half of these (17\%) use female sterilization. Despite the strong demand for permanent methods, vasectomy is used by less than one percent of all couples. In 2003, for example, Ministry of Health (MOH) surgeons performed only seven vasectomies. An ineffective service introduction model contributes to the low use of vasectomy. In the traditional model, doctors are sent to a hospital (often abroad) where a relatively high number of vasectomies are performed and the trainee is able to perform at least five supervised vasectomies. In their home practice, however, trained doctors frequently find a low demand and, unable to routinely perform vasectomies, soon lose their enthusiasm and surgical skills.

In 2005 FRONTIERS, the nongovernmental women's health organization APROVIME, and the Ministry of Health $(\mathrm{MOH})$ tested a new model for introducing sustainable no-scalpel vasectomy services in hospitals in Guatemala City. The model involved (1) training in vasectomy for the entire health team-including surgeons, nurses, receptionists, and others who might provide referrals - at facilities interested in providing the services; (2) providing counseling and information for potential clients; and (3) on-site training of surgeons with clients identified by the health teams. A project goal was to establish four vasectomy service centers, one of which could become a vasectomy training center.
To ensure motivation on the part of health teams, 15 hospitals and maternity clinics were invited to participate if they could identify at least one vasectomy candidate. Based on that criterion, six hospitals participated. The health teams at these hospitals, as well as those of adjacent facilities, attended workshops about vasectomy and received informational materials (a poster, a leaflet, and a brochure comparing female sterilization with vasectomy) to help them identify and counsel potential vasectomy clients. Over the course of 30 workshops in participating and adjacent facilities, 681 people received orientation on vasectomy.

Surgeons received training consisting of a halfday overview followed by a period of supervised practice. The number of sessions was not fixed, but continued until the trainee had attained the skills and the confidence to continue the procedure unsupervised. Surgeons who received certification were followed up after 22 weeks to determine whether they were still performing vasectomies. The model was evaluated using pre- and post-intervention questionnaires, service delivery statistics, and internal records.

\section{Results}

- The health teams generated 205 requests for vasectomies. A total of 158 vasectomies were performed in 54 surgical sessions, with an average of three vasectomies per session.

- A total of 14 surgeons began practical training. Of these, eight doctors from four hospitals 
and maternity centers completed their training and four surgeons from two hospitals were still in training by the end of the project.

- The training of the surgeons who were certified as vasectomy providers lasted an average of 12 weeks. On average, the surgeons required a total of 3.75 operating sessions and 8.25 vasectomies to be certified.

- Vasectomy services continued following the project's end. The four hospitals and maternity clinics carried out 28 surgery sessions with a total of 74 vasectomies during the 22-week period following the certification of surgeons. Follow-up visits one year after the end of the project showed that the four hospitals and maternities continued performing a similar number of vasectomies as during the project period. Two of these facilities potentially could become training centers for the expansion of vasectomy services.

- The project's total cost, including the time of all staff trained, was US\$43,355, or $\$ 4,335$ per certified surgeon trained. The training at adjacent health centers accounted for nearly half $(\$ 20,000)$ of this cost. Focusing on training only health teams at facilities providing vasectomy, using $\mathrm{MOH}$ trainers, and modifying follow-up procedures could significantly decrease costs. In the short term, the $\mathrm{MOH}$ could replicate the training for approximately $\$ 900$ per certified surgeon, and assuming demand rises over the long term, for about \$136 per surgeon.

- Multiple channels of outreach influenced the decision to undergo vasectomy (see Table). Referrals from neighboring facilities accounted for one-quarter of requests, but orientation of these facilities was a major expense. Health teams reported that successful strategies included providing information to postpartum women, giving out materials for men to hand out among friends, and distributing materials in waiting rooms.

\begin{tabular}{|c|c|c|}
\hline \multicolumn{3}{|c|}{$\begin{array}{l}\text { Sources of referral for vasectomy services, according to } \\
158 \text { service acceptors* }\end{array}$} \\
\hline & Referral (\%) & Information (\%) \\
\hline Wife & 29 & 68 \\
\hline Hospital staff (same) & 38 & 31 \\
\hline Hospital staff (other) & 25 & NA \\
\hline Friends, relatives & 18 & 21 \\
\hline
\end{tabular}

\section{Utilization}

- The $\mathrm{MOH}$ is presently scaling up training activities to six additional hospitals and maternity centers with support from USAID through URC's Calidad en Salud [Quality in Health] project.

\section{Policy Implications}

- The on-site training approach combined with a team-based referral and information system holds great potential for increasing use of vasectomy services. The model has proven to be sustainable and expandable, and has increased the number of vasectomies performed by the public sector from less than 10 in 2003 to over 200 in 2005.

- Training and certification for surgeons should be based on the instructor's assessment and the trainee's self-confidence, rather than on completion of a set minimum number of vasectomies during training.

September 2007

Source: de Rodríguez, Blanca, R. Vernon, and J. Solórzano. 2007. "Expanding access to vasectomy services in the Ministry of Health of Guatemala," FRONTIERS Final Report. Washington, DC: Population Council. Available on our website at www.popcouncil.org/frontiers/ frontiersfinalrpts.html or by e-mail:frontiers@popcouncil.org

This publication is made possible by the generous support of the American people through the United States Agency for International Development (USAID) under the terms of Cooperative Agreement No. HRN-A-00-98-00012-00. The contents are the responsibility of the FRONTIERS Program and do not necessarily reflect the views of USAID or the United States Government. 